\title{
Electrochemical properties of Sn-decorated SnO nanobranches as an anode of Li-ion battery
}

\author{
Jeong Ho Shin and Jae Yong Song ${ }^{*}$
}

\begin{abstract}
Sn-based oxide materials as an anode of lithium ion batteries (LIBs) suffer from the unavoidable mechanical stress originated from huge volume changes during lithiation/delithiation reactions. We synthesized the hierarchical SnO nanobranches (NBs) decorated with Sn nanoparticles on Cu current collector using a vapor transport method. The $\mathrm{Sn}$-decorated SnO NBs as an anode of LIB showed good electrochemical performance with high reversible capacity retention of as high as $502 \mathrm{mAh} / \mathrm{g}$ and rate capability of $455 \mathrm{mAh} / \mathrm{g}$ at a current density of $2.0 \mathrm{~A} / \mathrm{g}$ after 50 cycles. Through the morphological and crystal structure analyses after the charge and discharge processes, it was found that the morphology of Sn-decorated SnO NBs was transformed to nanoporous layered-structure, composed of Sn and lithium oxide, during the repeated lithiation/delithiation reactions. The free-volume of Sn-decorated SnO NBs and nanoporous layered-structure effectively accommodate the huge volume changes and enhance the electrochemical cyclability by facilitating the diffusion of Li-ions.
\end{abstract}

Keywords: SnO, Nanobranch, Electrochemical property, Phase transformation

\section{Background}

Rechargeable lithium ion batteries have been widely used as energy sources for portable electronic devices such as cellular phones, cameras, and lap-top computers. LIBs are also considered one of the most promising candidates for a next generation large-scale power source, i.e., electric vehicles (EVs) or hybrid electric vehicles (HEVs), because of their high energy density and good cyclability [1]. However, many critical challenges related to the improvement of LIB performance must still be addressed $[2,3]$. Among them, the energy density of the anode should be improved to meet the increasing demand for LIBs with higher energy density and power density. Although graphite has been commercialized as an anode material of LIBs due to its low operating voltage and excellent cyclability, its Li storage capacity is limited to the theoretical maximum capacity of $372 \mathrm{mAh} / \mathrm{g}$ [4]. Consequently, extensive studies have focused on

\footnotetext{
*Correspondence: jysong@kriss.re.kr

Korea Research Institute of Standards and Science, Materials Genome Center, Daejeon 34113, South Korea
}

developing new anode materials to replace graphite [5-7]. Among various anode materials, $\mathrm{Sn}$ has been investigated as an alternative candidate due to its high theoretical capacity of $994 \mathrm{mAh} / \mathrm{g}$ [8]. Unfortunately, it shows very poor cyclability due to deterioration of the anode caused by the huge volume expansion of $360 \%$ during the Li-Sn alloying process [9]. In order to overcome the anode failure related to the volume expansion, the use of a free-volume accommodating the volume expansion of the anode materials was suggested, e.g., in the form of nanowires, nanotubes, nanoparticles, porous structures, etc. [10-15]. Another approach is to prepare a composite structure of an active component in the inactive matrix, where the inactive matrix plays a role of accommodating the volume expansion of the active component during the lithiation process [16]. As the lithiation of Sn-based oxides such as $\mathrm{SnO}$ and $\mathrm{SnO}_{2}$ results in a composite structure of inactive lithium oxide and active Sn phases, the lithium oxide matrix helps to mitigate the large volume expansion. Generally, it is easier to synthesize the $\mathrm{SnO}_{2}$ phase than the $\mathrm{SnO}$ phase, because the latter is a metastable and low-temperature phase in the 
binary Sn-O system [17]. Nevertheless, many researchers have investigated various $\mathrm{SnO}$ nanostructures such as nanoparticles, nanosheets, nanoflowers, etc. as anode materials, because the theoretical capacity $(875 \mathrm{mAh} / \mathrm{g})$ of $\mathrm{SnO}$ is much higher than that $(783 \mathrm{mAh} / \mathrm{g})$ of $\mathrm{SnO}_{2}$ [18-21]. However, these fabrication methods require a binder and conductive carbon source, which reduces the anode capacity. Therefore, we were motivated to directly synthesize Sn nanoparticles (NPs) decorated $\mathrm{SnO}$ nanobranches (NBs) on a $\mathrm{Cu}$ current collector at $503 \mathrm{~K}$ without any additives. Herein, the electrochemical characteristics of the SnO NBs as an anode of LIBs were investigated together with the phase transformation and structural analysis.

\section{Methods}

The Sn-decorated SnO NBs were prepared by a vapor transport method. $\mathrm{Cu}$ foil $(18 \mu \mathrm{m}$ in thickness, 99.8 at \%, Nippon Foil Mfg Co.) was placed at the center of horizontal quartz tube which was evacuated to $5 \times 10^{-3}$ torr. The temperature of the tube center was set to $503 \mathrm{~K}$. Sn vapors evaporated from a resistanceheated tungsten boat were supplied by Ar carrier gas $(99.9 \%)$. The growth time of $\mathrm{SnO} \mathrm{NBs}$ was $2 \mathrm{~h}$. The detailed process can be found in the previous report [20]. The SnO film was synthesized by the same vapor transport method. When the mixture gas of $\mathrm{Ar}$ and $\mathrm{O}_{2}$ (Ar: $\mathrm{O}_{2}=98: 2$ ) was used instead of the Ar gas, SnO thin film (500 nm in thickness) grew on $\mathrm{Cu}$ substrate for $30 \mathrm{~min}$. The electrochemical properties of SnO NBs and $\mathrm{SnO}$ film as an anode of LIBs were investigated using a CR2032 coin cell. As a counter electrode, Li metal foil was used. The separator was microporous polyethylene (Celgard 2400, Celgard LLC. Charlotte, NC, USA) and the electrolyte was $1 \mathrm{~mol} / \mathrm{L}$ lithium hexafluorophosphate in a $1: 1(\mathrm{v} / \mathrm{v}$ ratio) mixture of ethylene carbonate and diethyl carbonate (Techno Semichem). The fabrication was conducted in Ar-filled glove box. The weights of all samples were measured using a microbalance (METTER TOLEDO, AT261). Cyclic voltammogram $(\mathrm{CV})$ curves were measured in the potential range of 0.001 to $2.5 \mathrm{~V}$ with a scan rate of $0.1 \mathrm{mV} / \mathrm{s}$ at room temperature using an electrochemical analyzer (Solartron 1280z). Galvanostatic charge/discharge measurements were carried out in the potential range of 0.001 to $2.5 \mathrm{~V}$ at the constant current of $0.1 \mathrm{~A} / \mathrm{g}$ using a multi-channel potentiostat/galvanostat (VMP3, Biologic). The C-rate was measured by varying the currents as $0.1,0.2,0.5$,
1.0 , and $2.0 \mathrm{~A} / \mathrm{g}$. The microstructures and crystal structures were analyzed using an X-ray diffraction (XRD. $\mathrm{Cu}-\mathrm{K} \alpha$, Bruker D8), field emission scanning electron microscope (SEM, Hitachi S4800), and field emission transmission microscope (TEM, FEI Tecnai F30).

\section{Results and discussion}

Figure 1 shows SEM morphologies and XRD patterns of as-prepared $\mathrm{Sn}$-decorated $\mathrm{SnO} \mathrm{NBs}$ and $\mathrm{SnO}$ film, which were grown on $\mathrm{Cu}$ foil, respectively. The $\mathrm{SnO}$ NBs with a length of approximately $5 \mu \mathrm{m}$ had a hierarchical structure of a backbone and secondary and tertiary branches, as shown in Fig. 1a. In the inset of Fig. 1a, the enlarged SEM image indicates that Sn nanoparticles (NPs) of 100 to $200 \mathrm{~nm}$ in diameter were decorated on the surface of the SnO NBs. The spherical nanoparticles were indexed to be a tetragonal crystal structure of metal $\mathrm{Sn}$, as confirmed by TEM analyses (see Additional file 1: Figure S1). The Fig. $1 \mathrm{~b}$ shows a typical SEM image of as-prepared $\mathrm{SnO}$ film with a thickness of $500 \mathrm{~nm}$. The XRD results show that the NBs were composed of SnO (JCPDS\#85-0712) and Sn (JCPDS\#86-2262), as shown in Fig. 1c. The SnO film was analyzed to be an amorphous phase. A more detailed description of the structural characteristics can be found in our previous report [22].

In order to get insight into the reaction behaviors of the $\mathrm{SnO} \mathrm{NBs}$ with $\mathrm{Li}^{+}$during the charge/discharge processes, cyclic voltammetry (CV) and ex situ XRD measurements were carried out. Figure 2a shows the first three CV curves of the SnO NBs in a voltage range of 0.001 to $2.5 \mathrm{~V}$ at a scan rate of $0.1 \mathrm{mV} / \mathrm{s}$. In the discharge process of the first cycle, the sharp cathodic peak at $0.9 \mathrm{~V}$ indicates that the $\mathrm{SnO} \mathrm{NBs}$ reacted with $\mathrm{Li}^{+}$to form $\mathrm{Li}_{2} \mathrm{O}$ and $\mathrm{Sn}$ as described in Eq. (1).

$$
\mathrm{SnO}+2 \mathrm{Li}^{+}+2 \mathrm{e}^{-} \rightarrow \mathrm{Sn}+\mathrm{Li}_{2} \mathrm{O}
$$

Since the Gibbs free energy change of Eq. (1) is given as $\Delta \mathrm{G}=-256.8 \mathrm{~kJ} / \mathrm{mol}$ at $298 \mathrm{~K}$, the reaction can spontaneously occur [23]. Here, the formation of $\mathrm{Li}_{2} \mathrm{O}$ is generally believed to be irreversible. With continuous discharging processes, several cathodic peaks appeared at 0.60, 0.30, and $0.16 \mathrm{~V}$, in sequence. These peaks were due to the lithiation reaction with forming $\mathrm{Li}_{x} \mathrm{Sn}$. The reactions can be given as follows:

$$
\mathrm{Sn}+x \mathrm{Li}^{+}+x \mathrm{e}^{-} \leftrightarrow \operatorname{Li}_{\mathrm{x}} \mathrm{Sn}(0 \leq x \leq 4.4)
$$

In the charge process, a series of conspicuous oxidation peaks appeared at the voltages of $0.52,0.63,0.73$, and 

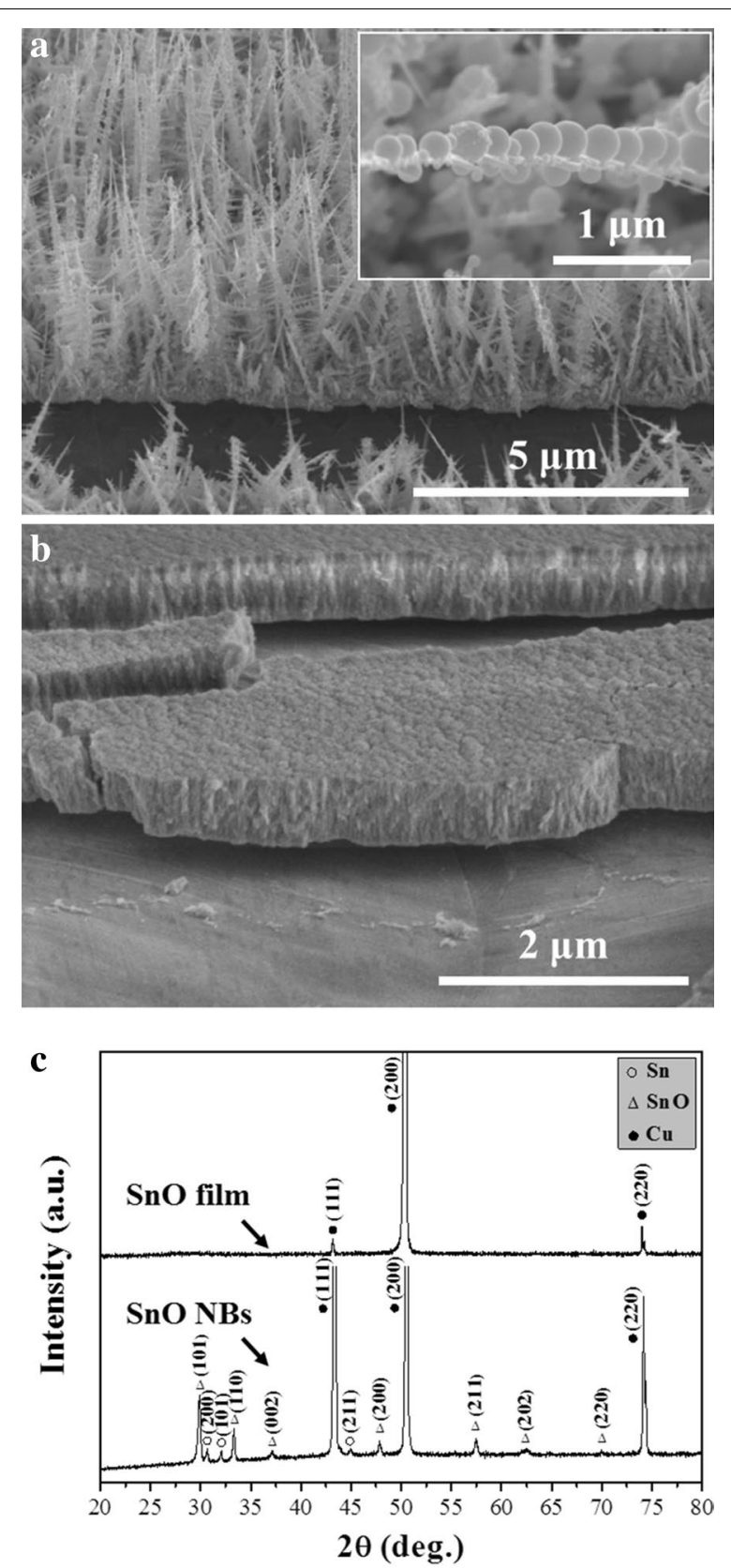

Fig. 1 Typical SEM image of (a) SnO NBs and (b) SnO film in the as-prepared state. The inset in a shows a high-magnified SEM image. c Typical XRD patterns of SnO NBs and SnO film in the as-prepared state

$0.80 \mathrm{~V}$, corresponding to the delithiation of $\mathrm{Li}_{22} \mathrm{Sn}_{5}, \mathrm{Li}_{7} \mathrm{Sn}_{2}$, $\mathrm{Li}_{7} \mathrm{Sn}_{3}$, and LiSn phases, respectively [24]. With further oxidation of charging process, a broad peak occurred at
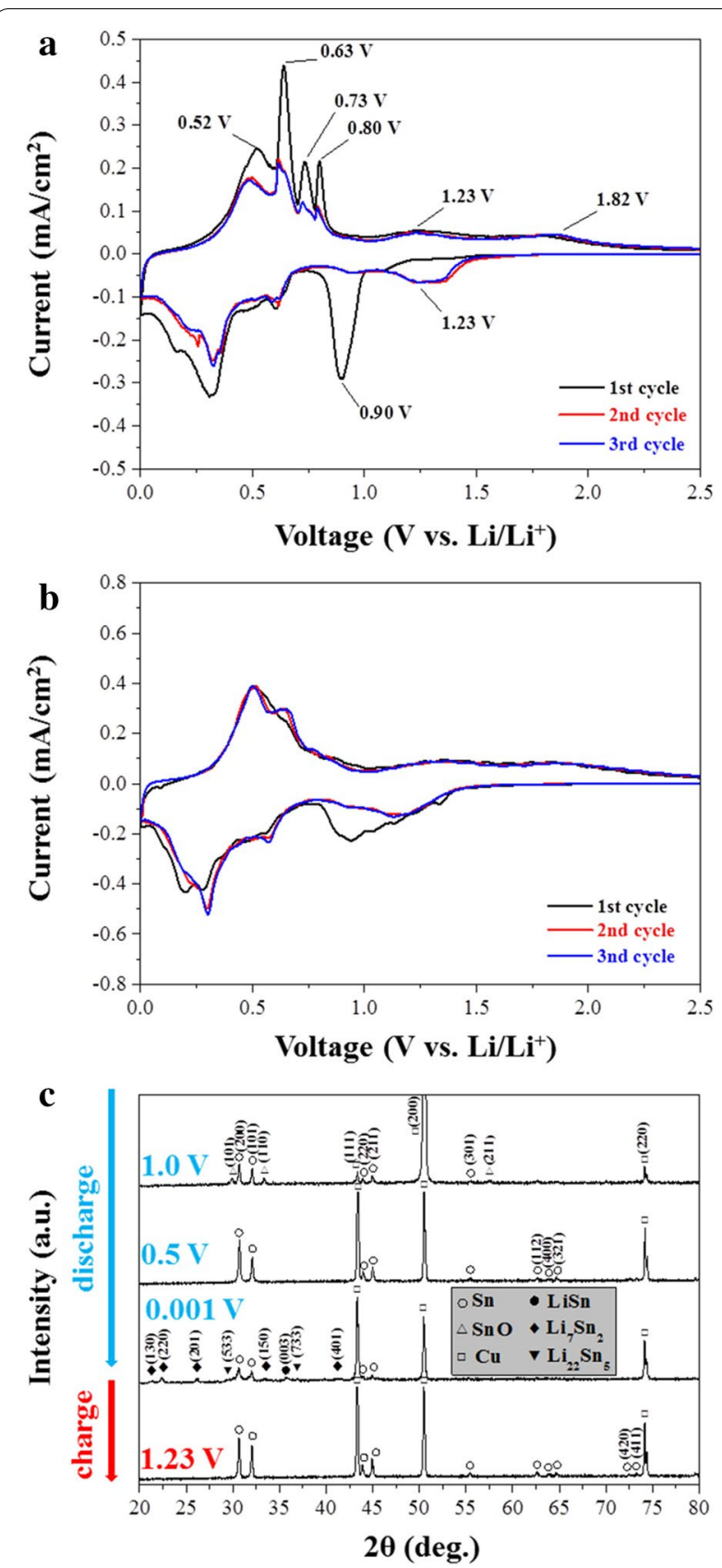

Fig. 2 Cyclic voltammetry (CV) profiles of (a) SnO NBs and (b) SnO film, c XRD patterns of the SnO NBs with the reaction potential with $\mathrm{Li}^{+}$in the first charge and discharge cycle

1.23 $\mathrm{V}$ due to the formation of Sn phase from the LiSn alloy [25]. Therefore, the Li-Sn alloying and dealloying reactions occurred reversibly, as described by Eq. (2). This 
result coincided with the charge/discharge profiles of $\mathrm{SnO}$ NBs in the voltage range of $0.001 \mathrm{~V}$ to $2.5 \mathrm{~V}$ at the current density of $0.1 \mathrm{~A} / \mathrm{g}$ (see Additional file 1: Figure S2a). Except for the first discharge process, the subsequent charge/discharge curves showed highly reversible behavior. The irreversible discharge capacity (about $190 \mathrm{mAh} / \mathrm{g}$ ) of the first cycle was ascribed to the formation of $\mathrm{Li}_{2} \mathrm{O}$ and $\mathrm{Sn}$ from $\mathrm{SnO}$ phase according to Eq. (1). Figure $2 \mathrm{~b}$ shows the $\mathrm{CV}$ curve of the $\mathrm{SnO}$ film in comparison with the electrochemical behaviors of the SnO NBs. Interestingly, it was found that the representative sharp and stepwise reaction peaks (cathodic and oxidation peaks) observed in Fig. 2a did not appear in the CV curves of SnO film. The reaction peaks during the first cycle of SnO film appeared sharper than those during subsequent cycles, although the peak potentials of $\mathrm{SnO}$ films were equal to those of SnO NBs. The broad reaction peaks of the subsequent cycles indicated that the film structure without a free-volume suppressed the volume expansion and then the reaction of Eq. (2) was difficult to occur. Therefore, the average capacities of SnO films were $40 \%$ lower than those of SnO NBs during the initial five cycles, as shown in the charge/discharge profiles (see Additional file 1: Figure S2b).

This might be attributed to the morphological difference between nanobranch and film structures. That is, the hierarchical structures of the SnO NBs with free-volume provide the $\mathrm{Li}$ ions with short diffusion path and facilitate the sequential $\mathrm{Li}-\mathrm{Sn}$ alloying and dealloying reactions, while the dense structure of SnO film plays a role of diffusion barrier. On the other hand, a weak and broader oxidation peaks were observed near $1.82 \mathrm{~V}$ in Fig. 2a. This was ascribed to the formation of $\mathrm{SnO}$ phase [26]. According to the in situ Mössbauer spectroscopy experiment of Dahn and co-workers, $\mathrm{SnO}$ could be regenerated to some extent by the reaction of $\mathrm{Sn}$ and oxygen, which was subsequently liberated due to the reduction of $\mathrm{Li}_{2} \mathrm{O}$ in the charging process [27]. In the subsequent cycles (second and third cycles), the alloying and dealloying reactions almost coincided with those of the first cycle, despite the decreasing peak intensities and slight shift of peak voltages. It is noted that the peak at $0.90 \mathrm{~V}$ disappeared and a new broad peak appeared near $1.23 \mathrm{~V}$ in the discharge process. This agreed well with previous reports that the broad cathodic peak near $1.23 \mathrm{~V}$ represent the formation of lithium oxide from the $\mathrm{SnO}$ phase formed around $1.82 \mathrm{~V}$ in the charging process $[25,26,28]$. This agreed with the result that the cathodic peak at $1.23 \mathrm{~V}$ and the oxidation peak at $1.82 \mathrm{~V}$ reversibly appeared in the second and third cycles.
Figure 2c shows the variations of XRD patterns of the SnO NBs with the discharge and charge voltages of the first cycle. After discharging up to $1.0 \mathrm{~V}$, the overall peak intensities were reduced in comparison with those in the as-prepared state (Fig. 1c). This was related to the decomposition reaction of Eq. (1). When the discharging process was conducted up to $0.5 \mathrm{~V}$, the XRD peaks of SnO phase disappeared and only the peaks of Sn phase remained. This is attributed to the complete reduction of $\mathrm{SnO}$ to $\mathrm{Sn}$ and $\mathrm{Li}_{2} \mathrm{O}$ phases, which agrees with the increased peak intensities of the $\mathrm{Sn}$ phases. The XRD peaks of the $\mathrm{Li}_{2} \mathrm{O}$ phase were not observed due to its amorphous character. With further discharging up to $0.001 \mathrm{~V}$, various XRD peaks of $\mathrm{Sn}$ and $\mathrm{Li}_{\mathrm{x}} \mathrm{Sn}$ alloys such as $\mathrm{LiSn}, \mathrm{Li}_{7} \mathrm{Sn}_{2}$, and $\mathrm{Li}_{22} \mathrm{Sn}_{5}$ phases appeared. Despite the complete discharging process, the appearance of LiSn, $\mathrm{Li}_{7} \mathrm{Sn}_{2}$ and $\mathrm{Sn}$ phases indicates that incomplete lithiation of $\mathrm{SnO}$ NBs occurred in the first cycle. After charging up to $1.23 \mathrm{~V}$ in the first cycle, the XRD peaks of Li-Sn alloys completely disappeared and only the XRD peaks of $\mathrm{Sn}$ phase existed following the reversible reaction of Eq. (2).

Galvanostatic charge/discharge tests were conducted to evaluate the electrochemical performance of Sn-decorated $\mathrm{SnO} \mathrm{NBs}$ as anode materials for LIBs. Figure 3a shows the cycling properties of $\mathrm{SnO}$ NBs and films during 50 cycles. The cyclability was measured between 0.001 and $1.0 \mathrm{~V}$ at the current density of $0.1 \mathrm{~A} / \mathrm{g}$. The $\mathrm{SnO}$ film exhibited capacity retention of $342 \mathrm{mAh} / \mathrm{g}$ after 50 cycles with the maximum capacity of $375 \mathrm{mAh} / \mathrm{g}$. It is notable that the $\mathrm{SnO}$ NBs showed much higher reversible capacity retention of $502 \mathrm{mAh} / \mathrm{g}$ up to 50 cycles with a stable cycling performance. Even though the specific capacity of SnO NBs slowly decreased with the number of cycles, their cyclability and capacity retention values were comparable to those of other nanostructured $\mathrm{SnO}$ anode materials [18-21]. Therefore, it is supposed that the higher capacity of the SnO NBs is attributed to: (i) the large amount of Sn nanoparticles existing on the surface of $\mathrm{SnO}$ NBs and (ii) the branched nanostructures and nanoporous layered structure with free-volume facilitating faster $\mathrm{Li}^{+}$diffusion and accommodating the volume expansion caused by lithiation.

The rate capability of the $\mathrm{SnO} \mathrm{NBs}$ was also evaluated with variation of the current densities from 0.1 to $2.0 \mathrm{~A} / \mathrm{g}$. The SnO NBs exhibited excellent rate capability, as shown in Fig. 3b. The reversible capacities at voltage of $1.0 \mathrm{~V}$ were observed in the range of $616-455 \mathrm{mAh} / \mathrm{g}$ with a Coulombic efficiency of $97 \%$. This was much higher than the theoretical capacity $(372 \mathrm{mAh} / \mathrm{g})$ of graphite. 


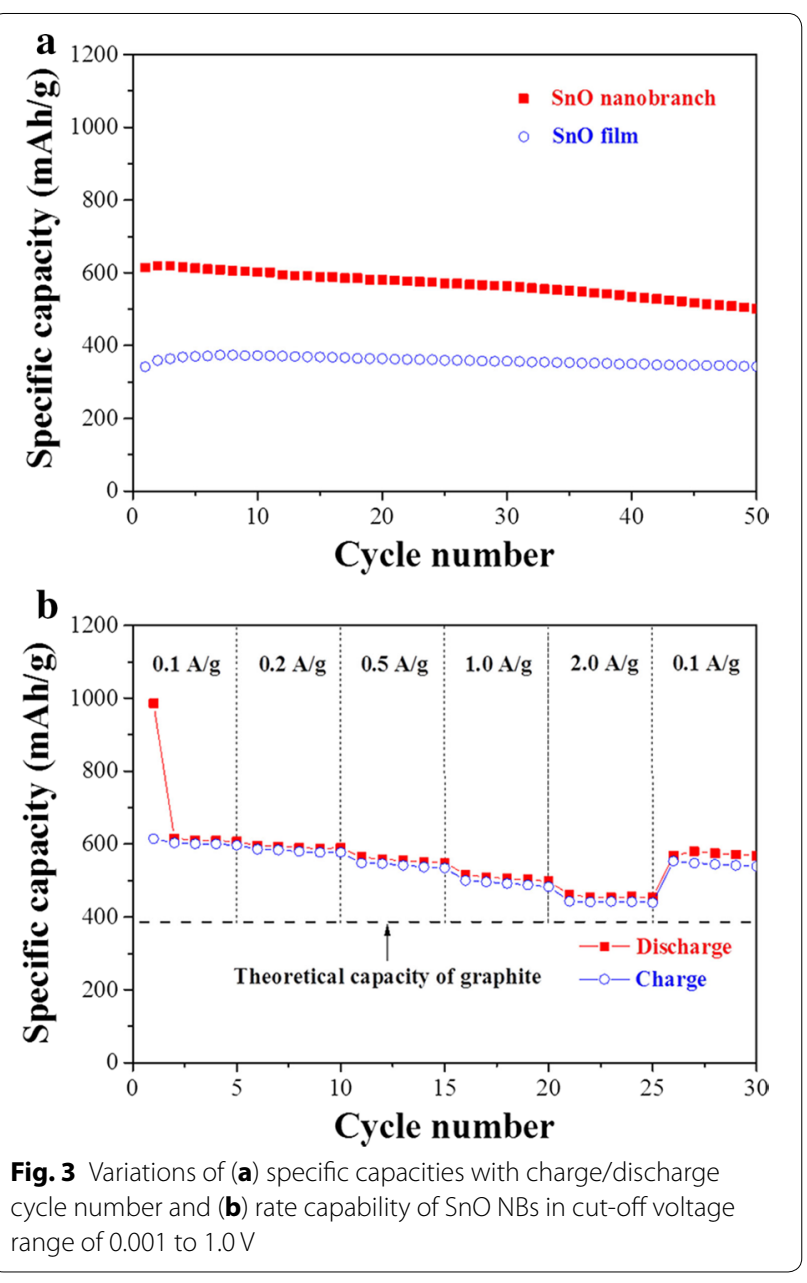

Figure 4 shows the typical microstructural changes of $\mathrm{SnO}$ film and SnO NBs with charge/discharge cycles at a rate of $0.1 \mathrm{~A} / \mathrm{g}$. As shown in Fig. $4 \mathrm{a}, \mathrm{SnO}$ film still had a dense layered structure after 50 cycles. In comparison, the hierarchical structure of Sn-decorated SnO NBs remained more or less after the first cycle, even though they were thickened due to the lithiation (Fig. 4b). The inset of Fig. 4b show a high-resolution TEM image of a Sn-decorated SnO NB after the first cycle and a corresponding Fast Fourier Transform (FFT) image of the marked area. The FFT image was indexed to the tetragonal crystal structure of metal Sn. This indicates that the SnO NBs were transformed to a composite structure of an amorphous lithium oxide and nanosized Sn although lithium oxide phase was not indexed due to its amorphous character. After 10 cycles, the branched nanostructure still remained at the top side while nanoporous structure appeared at the bottom (Fig. 4c). Figure $4 \mathrm{~d}$ shows the higher magnified SEM image of the area marked by the white rectangle in Fig. 4c. It was noted that some of the branched nanostructures agglomerated. After 50 cycles, the SnO NBs were fully transformed to highly nanoporous layered structure (Fig. 4e). As shown in the magnified image (Fig. 4f), the porous layer was composed of networked nanopores (several tens of hundreds of nanometers in diameter). The microstructural transformation from hierarchical nanobranches to a nanoporous layered structure might be responsible for the high reversible capacity retention of the SnO NBs, as shown in Fig. 3. Although the original morphology of the SnO NBs was completely transformed to the networked nanoporous layer, the porous structure still has significant specific surface area and free volume.

Therefore, it is supposed that the higher electrochemical performance of the $\mathrm{SnO} \mathrm{NBs}$, in comparison with $\mathrm{SnO}$ films, can be attributed to: (i) morphological advantages i.e., branched nanostructures and nanoporous layered structure including large free-volume, which provides fast diffusion channels for $\mathrm{Li}^{+}$and accommodates the huge volume changes following the $\mathrm{Li}-\mathrm{Sn}$ alloying and dealloying reactions [29]; (ii) the inactive lithium oxide that forms at the voltage of $0.9 \mathrm{~V}$ during the first discharge, mitigates the volume expansion [30]; and (iii) $\mathrm{Sn}$ NPs decorated on the surface of SnO NBs increases the electrochemical capacity [31].

\section{Conclusions}

Sn-decorated $\mathrm{SnO}$ NBs were directly synthesized on a $\mathrm{Cu}$ foil by a vapor transport process. The SnO NBs as an anode of a LIB exhibited a high reversible capacity of approximately $502 \mathrm{mAh} / \mathrm{g}$ up to 50 cycles as well as a high rate capability of $455 \mathrm{mAh} / \mathrm{g}$ at a rate of $2.0 \mathrm{~A} / \mathrm{g}$. The excellent electrochemical performance of Sn-decorated SnO NBs is attributed to the free-volume of the nanostructures as well as the decorated Sn nanoparticles. Microstructural studies revealed that, during the charge/ discharge processes, the nanobranches transformed to nanoporous layered structure. Both nanostructures, which include free-volumes, facilitates fast $\mathrm{Li}^{+}$diffusion and accommodates the huge volume changes. It is suggested that hierarchical and/or nanoporous nanostructures will be one of potential ways in enhancing the electrochemical performance of other anode materials of LIBs. 

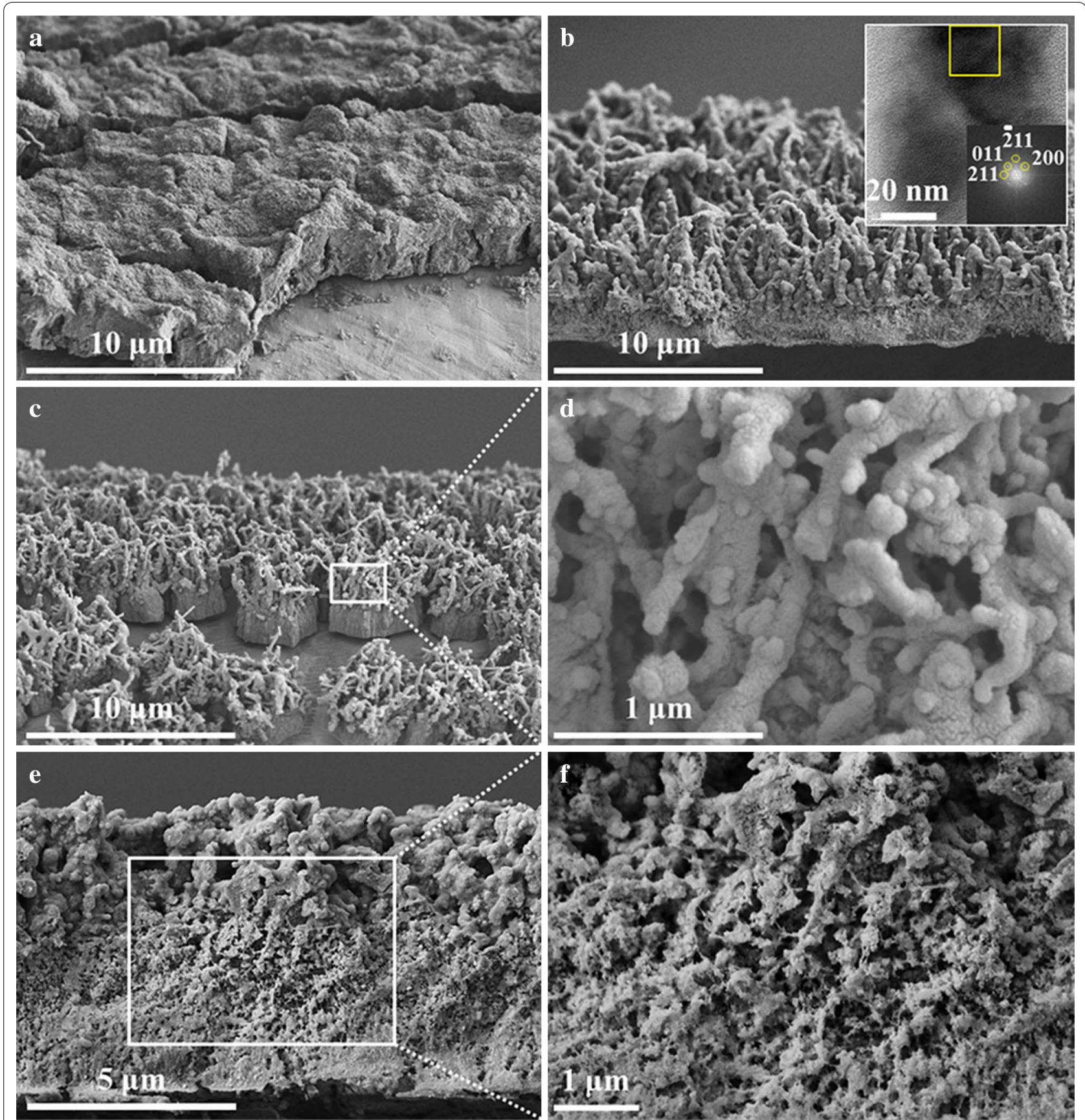

Fig. 4 Morphological changes of SnO film and SnO NBs with charge/discharge cycling processes. Cross-sectional SEM image of (a) SnO film after 50 cycles and (b) SnO NBs after the first cycle. The insets in b show an HRTEM image and the corresponding FFT image of a hierarchical SnO NB after the first cycle. $\mathbf{c}$ SEM image of SnO NBs after 10 cycles, $\mathbf{d}$ magnified SEM image of the area marked in $\mathbf{c}$, e cross-sectional SEM image of SnO NBs after 50 cycles, (f) magnified SEM image of the area marked in (e)

\section{Additional file}

Additional file 1. Electronic supporting information includes additional TEM images and electrochemical properties.

\section{Authors' contributions}

$J \mathrm{H}$ carried out experiments and JY initiated the idea and wrote the manuscript. Both authors read and approved the final manuscript. 


\section{Acknowledgements}

This work was supported by the R\&D Convergence Program of National Research Council of Science \& Technology (Grant No. B551179-13-01-03) funded by MSIP of Republic of Korea.

\section{Competing interests}

The authors declare that they have no competing interests.

Received: 23 December 2015 Accepted: 18 March 2016 Published online: 01 May 2016

\section{References}

1. B. Scrosati, J. Garche, Lithium batteries: status, prospects and future. J. Power Sour. 195, 2419 (2010)

2. H. Li, Z. Wang, L. Chen, X. Huang, Research on advanced $m$, terials for Liion batteries. Adv. Mater. 21, 4593 (2009)

3. D. Liu, G. Cao, Engineering nanostructured electrodes and fabrication of film electrodes for efficient lithium ion intercalation. Energ. Envirn. Sci. 3 1218 (2010)

4. K. Tokumitsu, H. Fujimoto, A. Mabuchi, T. Kasuh, High capacity carbon anode for Li-ion battery a theoretical explanation. Carbon 37, 1599 (1999)

5. Y. Idota, T. Kubota, A. Matsufuji, Y. Maekawa, T. Miyasaka, Tin-based amorphous oxide: a high-capacity lithium-ion-storage material. Science $\mathbf{2 7 6}$, 1395 (1997)

6. C.K. Chan, H. Peng, G. Liu, K. Mcilwrath, X.F. Zhang, R.A. Huggins, Y. Cui, High-performance lithium battery anodes using silicon nanowires. Nat. Nanotechnol. 3, 31 (2008)

7. T. Djenizian, I. Hanzu, P. Knauth, Nanostructured negative electrodes based on titania for Li-ion microbatteries. J. Mater. Chem. 21, 9925 (2011)

8. J.W. Park, J.Y. Eom, H.S. Kwon, Charge-discharge characteristics of a layered-structure electroplated Cu/Sn anode for Li-ion batteries. Electrochim. Acta 55, 1825 (2010)

9. N. Tamura, R. Ohshita, M. Fujimoto, M. Kamino, S. Fujitani, Advanced structres in electrodeposited tin base negative electrodes for lithium secondary batteries. J. Electrochem. Soc. 150, A679 (2003)

10. Z. Ying, Q. Wan, H. Cao, Z.T. Song, S.L. Feng, Characterization of $\mathrm{SnO}_{2}$ nanowires as an anode material for Li-ion batteries. Appl. Phys. Lett. 87, $113108(2005)$

11. M.S. Park, Y.M. Kang, G.X. Wang, S.X. Dou, H.K. Liu, The effect of morphological modification on the electrochemical properties of $\mathrm{SnO}_{2}$ nanomaterials. Adv. Funct. Mater. 18, 455 (2008)

12. H. Wang, Y. Wu, Y. Bai, W. Zhou, Y. An, J. Li, L. Guo, The self-assembly of porous microspheres of tin dioxide octahedral nanoparticles for high performance lithium ion battery anode materials. J. Mater. Chem. 21, 10189 (2011)

13. H.S. Kim, J.P. Cho, Hard templating synthesis of mesoporous and nanowire $\mathrm{SnO}_{2}$ lithium battery anode materials. J. Mater. Chem. 18, 771 (2008)

14. W.J. Jo, U.K. Cheang, M.J. Kim, Development of flagella bio-templated nanomaterials for electronics. Nano Convergence. 1, 10 (2014)
15. S.A. Han, R. Bhatia, S.W. Kim, Synthesis, properties and potential applications of two-dimensional transition metal dicholcogenides. Nano Converg. 2, 17 (2015)

16. M. Winter, J.O. Besenhard, Electrochemical lithiation of tin and tin-based intermetallics and composites. Electrochim. Acta 45, 31 (1999)

17. S. Cahen, N. David, J.M. Fiorani, A. Maître, M. Vilasi, Thermodynamic modelling of the O-Sn system. Thermochim. Acta 403, 275 (2003)

18. J. Ning, T. Jiang, K. Men, Q. Dai, D. Li, Y. Wei, B. Liu, G. Chen, B. Zou, G. Zou, Syntheses, characterizations, and applications in lithium ion batteries of hierarchical Sno nanocrystals. J. Phys. Chem. C 113, 14140 (2009)

19. J. Ning, Q. Dai, T. Jiang, K. Men, D. Liu, N. Xiao, C. Li, D. Li, B. Liu, B. Zou, G. Zou, W.W. Yu, Facile synthesis of tin oxide nanoflowers: a potential highcapacity lithium-ion-storage material. Langmuir 25, 1818 (2009)

20. H. Uchiyama, E. Hosono, I. Honma, H. Zhou, H. Imai, A nanoscale meshed electrode of single-crystalline $\mathrm{SnO}$ for lithium-ion rechargeable batteries. Electrochem. Commun. 10, 52 (2008)

21. M.Z. Iqbal, F. Wang, H. Zhao, M.Y. Rafique, J. Wang, Q. Li, Structural and electrochemical properties of $\mathrm{SnO}$ nanoflowers as an anode material for lithium ion batteries. Scripta Mater. 67, 665 (2012)

22. J.H. Shin, Y.H. Kim, H.M. Park, J.Y. Song, Low temperature and self-catalytic growth of tetragonal SnO nanobranch. Mater. Lett. 64, 1120 (2010)

23. R.A. Huggins, Advanced batteries-materials science aspects (Springer, New York, 2009), p. 152

24. Z. Chen, Y. Cao, J. Qian, X. Ai, H. Yang, Facile synthesis and stable lithium storage performances of $\mathrm{Sn}$ - sandwiched nanoparticles as a high capacity anode material for rechargeable Li batteries. J. Mater. Chem. 20, 7266 (2010)

25. M. Mohamedi, S.J. Lee, D. Takahashi, M. Nishizawa, T. Itoh, I. Uchida, Amorphous tin oxide films: preparation and characterization as an anode active material for lithium ion batteries. Electrochim. Acta 46, 1161 (2001)

26. D. Aurbach, A. Nimberger, B. Markovsky, E. Levi, E. Sominski, A. Gedanken, Nanoparticles of SnO produced by sonochemistry as anode materials for rechargeable lithium batteries. Chem. Mater. 14,4155 (2002)

27. I.A. Courtney, R.A. Dunlap, J.R. Dahn, In-situ ${ }^{119}$ Sn Mössbauer effect studies of the reaction of lithium with $\mathrm{SnO}$ and $\mathrm{SnO}: 0.25 \mathrm{~B}_{2} \mathrm{O}_{3}: 0.25 \mathrm{P}_{2} \mathrm{O}_{5}$ glass. Electrochim. Acta 45, 51 (1999)

28. S.J. Han, B.C. Jang, T.A. Kim, S.M. Oh, T.H. Hyeon, Simple synthesis of hollow tin dioxide microspheres and their application to lithium-ion battery anodes. Adv. Funct. Mater. 15, 1845 (2005)

29. W. Zhou, C. Cheng, J. Liu, Y.Y. Tay, J. Jiang, X. Jia, J. Zhang, H. Gong, H.H. $\mathrm{Hng}, \mathrm{T}$. Yu, H.J. Fan, Epitaxial growth of branced a- $\mathrm{Fe}_{2} \mathrm{O}_{3} / \mathrm{SnO}_{2}$ nano-heterostructures with improved lithium-ion battery performance. Adv. Funct. Mater. 21, 2439 (2011)

30. H.G. Kim, S.W. Kim, Y.U. Park, H.K. Gwon, D.H. Seo, Y.H. Kim, K.S. Kang, SnO graphene composite with high lithium storage capability for lithium rechargeable batteries. Nano Res. 3, 813 (2010)

31. P. Meduri, C. Pendyala, V. Kumar, G.U. Sumanasekera, M.K. Sunkara, Hybrid tin oxide nanowires as stable and high capacity anodes for Li-ion batteries. Nano Lett. 9, 612 (2009)

\section{Submit your manuscript to a SpringerOpen ${ }^{\circ}$ journal and benefit from:}

- Convenient online submission

- Rigorous peer review

- Immediate publication on acceptance

- Open access: articles freely available online

- High visibility within the field

- Retaining the copyright to your article

Submit your next manuscript at springeropen.com 